Revista de Comunicación y Salud, 2020, Vol. 10, no 3, pp. 23-32

Editado por Cátedra de Comunicación y Salud

ISSN: 2173-1675

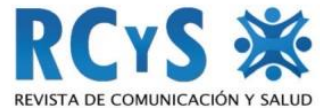

Enviado 30 de abril de 2020

Aprobado 30 de junio de 2020

\title{
EL DESAFÍO DE CONSTRUIR IMÁGENES MENTALES DE LAS ENFERMEDADES CRÓNICAS NO TRANSMISIBLES EN PACIENTES ASINTOMÁTICOS
}

\author{
The challenge of building mental images of chronical non transmissible \\ diseases in asymptomatic patients
}

\author{
Miguel Ángel Carrasco Garcia ${ }^{1}$ \\ miguel.carrasco@alumnos.uach.cl \\ Ricardo Andrés Neira Mellado \\ Universidad Austral de Chile. Chile \\ ricardo.neira@uach.cl \\ Paulina Lisbett Fierro Pinot \\ paulylis@hotmail.com
}

Universidad Austral de Chile-Universidad de la Frontera. Chile.

\section{Resumen}

En las primeras etapas de la enfermedad, la diabetes, la hipertensión o la dislipidemia, pueden ser asintomáticas para la mayoría de los pacientes. Por ello, es una tarea compleja para el equipo de salud encontrar la forma de explicarles que padecen de una patología que "silenciosamente" los daña a nivel neurovascular. Si una persona no tiene una imagen mental de su enfermedad, difícilmente podrá tomar conciencia de los riesgos que corre si no logra compensarse adecuadamente. La construcción de imágenes mentales de las patologías crónicas es una tarea pendiente en Salud Primaria, área en la que tanto la educación como el rol de la comunicación han sido relegadas a un segundo plano. Los profesionales de la salud primaria deben generar junto a sus pacientes, una co-construcción de las imágenes mentales de sus enfermedades. Esta nueva visión, implica que el profesional deberá insertarse en el contexto del paciente y desde ahí iniciar una exploración y explicación de cada realidad.

Palabras clave: Imágenes mentales; Comunicación en salud; Enfermedades crónicas; Adherencia terapéutica; Medicina.

\section{Abstract \\ During an early stage of diagnosis, diabetes, hypertension or dyslipidemia can be considered asymptomatic for most patients. Hence, how to explain their pathologies is}

1 Miguel Angel Carrasco García. Universidad Austral de Chile- Universidad de la Frontera. miguel.carrasco@alumnos.uach.cl Periodista y Médico Cirujano de la Universidad Austral de Chile (UACH). Diplomado en medicina Familiar, Universidad de la Frontera (UFRO). MBA en Salud, Universidad Andrés Bello. Estudiante Doctorado en Comunicación UACH-UFRO. 
framed for patients becomes a challenging task, especially for acknowledging the risks associated with diseases with a high rate of neurovascular damage. The construction of mental images of chronic pathologies is a pending task in Primary Health systems, which deny education and communication as essential assets for clinical treatments. In this sense, efforts from the health professionals are required to jointly create mental images of the diseases with their patients. This approach implies new communication dynamics, which promote acknowledgement of the economical, social, and cultural context of the patient in order to explain and explore the patient's reality.

Keywords: Mental images; Health communication; Chronic diseases; Treatment adherence; Medicine.

\section{Cómo citar el artículo}

Carrasco García, M. E., Neira Mellado, R. A. \& Fierro Pinot, P. L. (2020). El desafío de construir imágenes mentales de las enfermedades crónicas no transmisibles en pacientes asintomáticos. Revista de Comunicación y Salud, 10 (3), 23-32. doi: https://doi.org/10.35669/rcys.2020.10(3).23-32

\section{INTRODUCCIÓN}

Actualmente, uno de los principales problemas de salud pública son las enfermedades crónicas no transmisibles, donde la diabetes, hipertensión y obesidad son las tres afecciones más frecuentes en la población. Las estadísticas demuestran que tres de cada cuatro muertes en el mundo son atribuibles a dichas patologias representando además la mayor carga de salud en los países industrializados y posicionandose como un problema en acelerado incremento para países subdesarrollados (Moiso, 2007).

La adherencia terapéutica es una de las principales estrategias usadas en la lucha contra estas enfermedades, y es definida como el contexto en el cual el comportamiento de la persona coincide con las recomendaciones relacionadas con la salud, e incluyen la capacidad del paciente para asistir a citas programadas, tomar los medicamentos tal y como se indican, realizar los cambios en el estilo de vida recomendados y por último completar los estudios de laboratorio o pruebas solicitadas (Peralta y Carbajal, 2008).

¿Cómo se convence al portador de una patología asintomática que debe acatar las indicaciones del equipo de salud? Lograr la adherencia terapéutica es un problema multidimensional, donde las ideas o representaciones que tienen los pacientes sobre las enfermedades que sufren y sobre el tratamiento que les prescriben marcan su pronóstico (Ramos, 2015).

Por décadas, el enfrentamiento terapéutico de las enfermedades ha empleado como pilar al modelo biomédico, útil e infalible con las enfermedades agudas (que duelen, sangran y hospitalizan), pero insuficiente con aquellas que son asintomáticas. Si la persona no percibe un síntoma ni tampoco ve un signo clínico, no podrá construir una 
imagen mental de la dislipidemia (colesterol alto que causa la mayoría de los infartos) y sin esta representación, es altamente probable, que las indicaciones médicas caigan en terreno infértil.

\section{OBJETIVO}

Este trabajo busca reflexionar respecto a la importancia de las imágenes mentales en el tratamiento de las patologías crónicas como la diabetes, la hipertensión y la dislipidemia, las cuales en sus primeras etapas son asintomáticas y requieren de enormes esfuerzos del equipo de salud para lograr adherencia terapéutica.

\section{LAS IMÁGENES}

Para Villafañe (1992), en la imagen existe una una selección de la realidad, elementos configurantes y una sintaxis entendida como una manifestación de orden. "Todo fenómeno que admita reducirse de esta manera, sin alterar su naturaleza, puede considerarse una imagen" (p.30), y su estudio puede reducirse a dos grandes procesos: la percepción, con sus mecanismos de selección de la realidad, y la representación, con la explicitación de una forma particular de tal realidad o un aspecto de ella.

Si bien todas las imágenes deben tener correlato de la realidad, el individuo puede crear imágenes en base a su aprendizaje y a ideas generadas en el sustento de la experiencia. Frusser (citado en Soto, 2015), explica que la imaginación es la capacidad específica de crear y descifrar imágenes; sin embargo, la imaginación por sí sola no es suficiente para la creación de tales imágenes. Lo que es visto debe ser fijado y tornarse accesible para otros. Debe ser reconvertido en símbolos, y ese código resultante posteriormente debe ser alimentado en la memoria y descifrado por otros. Tradicionalmente, la imaginación ha jugado un rol fundamental en el proceso de conocer, pues se ha estimado que de ella emergen los modos que construye el hombre para intermediar con el mundo; es la manera que este tiene para acceder a él desde su exisistencia, en otras palabras, desde fuera de él.

Las imágenes pueden ser descritas como endógenas, cuyo ejemplo son los recuerdos, y exógenas, las cuales necesitan de un soporte técnico para alcanzar nuestra mirada. Estas imágenes endógenas no siempre son de naturaleza individual, pueden tener un origen colectivo y las personas, sin darse cuenta, las incorporan como propias, influenciados por los medios de masas (Belting, 2007).

A las imágenes suele otorgarles la expresión de un significado y la duración de un recuerdo personal, estando sujetas a la autocensura (Belting, 2007). Por lo tanto, la experiencia con imágenes se basa en una construcción que el propio sujeto elabora y está determinada por las condiciones particulares en que son mediadas y modeladas; esta especie de metamorfosis ocurre cuando las imágenes de algo que ocurrió se transforman en recuerdos. 


\subsection{La Imagen Mental.}

Según la psicología cognitiva "Las imágenes no son sólo un tipo de código destinado a favorecer el recuerdo, sino que parecen desempeñar un papel central en el pensamiento creativo" (Otero, 2016, p. 96)

Para el grupo de Innovación Docente Imagen y $\operatorname{Texto}^{2}$ de la Universidad de Granada (2011) las imágenes mentales constituyen representaciones internas del conocimiento y pertenecen al plano del concepto, ya que son el resultado de la manipulación de entidades simbólicas en el procesamiento dinámico de la información. Las imágenes mentales ayudan a disminuir la carga que se envía a la memoria de trabajo y de esta forma aumenta la eficacia de los procesos de comprensión.

Para activar todos los procesos involucrados en la transformación de las imágenes físicas a las mentales, la percepción es fundamental, al igual que la memoria definida por Ballesteros (1999) como un proceso psicológico que sirve para almacenar información codificada, la cual puede ser recuperada, unas veces de forma voluntaria y consciente, y otras de manera involuntaria.

En relación a cómo se forman las imágenes, la teoría de la codificación dual explica que las personas tienen dos formas de representación: el sistema verbal y el sistema de imagen. Este último especializado en el procesamiento de la información concerniente a objetos y eventos no verbales, concretos, sensoriales, cuya función principal es la generación y procesamiento de imágenes mentales (Fernández, 2013).

Con una fuerte carga subjetiva, la imaginería mental es un término que hace referencia a las representaciones mentales que dan la experiencia de percepción sin la presencia de un estímulo sensorial aferente. Serían las imágenes sonoras de los signos lingüísticos, versus las visuales, mejores para explicar la participación de las imágenes en la forma de materializarse el pensamiento conceptual ideativo (Martinez, 2014). Sin embargo, la mayoría de las investigaciones se han centrado en el estudio de las imágenes mentales visuales y casi no hay investigaciones centradas en las imágenes relacionadas con los demás sentidos (Pardos, 2017).

Las imágenes mentales también pueden tener un sustrato propioceptivo a través de movimientos que "proporcionan al perceptor información cinestésica obtenida a partir de los músculos, tendones y articulaciones" (Ballesteros, 1999, p.709). La ausencia de este sentido, que puede causar una pérdida del cuerpo, puede tener una causa que nada tiene que ver con la fisiología: Baitello (2005) explica que factores sociales y culturales, como la hipertrofia de la comunicación por parte de las imágenes, pueden alterar la propiocepción, la sensación del propio cuerpo, del espacio y del yo.

A pesar de los avances en el estudio de estas representaciones y los procesos involucrados en su génesis y evocación, todavía hay mucha incertidumbre y no existe total claridad entre la conexión generada por las imágenes mentales y el pensamiento, principalmente por la variedad de imágenes mentales que existen, y la diversidad de

${ }^{2}$ http://www.ugr.es/ imagenytexto/trad/

Revista de Comunicación y Salud, 2020, Vol. 10, n 3, pp. 23-32 
formas de pensar (Campos y González, 2017). Sin embargo, existe cierto consenso en que las imágenes mentales están presentes al momento de pensar y tomar decisiones.

\subsection{Las Imágenes y los Medios de In-Comunicación}

Diariamente las personas están expuestas a imágenes de elementos y temas, la mayor parte de ellas provenientes de los medios de comunicación. Dichos medios, son generadores de valores sociales por medio de imágenes, difundiendo y creando estereotipos culturales, algunos de los cuales giran alrededor de una sobre estimación de la imagen cultural (Herrero, 2005) lo que ha llevado a un bombardeo excesivo de imágenes circulantes en detrimento de la propia comunicación (Browne, 2006). Esta proliferación indiscriminada y compulsiva de imágenes exógenas en todos los tipos de espacios mediáticos generan en los receptores la compulsión exacerbada de apropiación (Baitello, 2004). Surge entonces la iconofagia (impura) donde los cuerpos devoran las imágenes que llegan a través de la propaganda, la moda, los estilos de vida y los medios de comunicación.

Un consumo indiscriminado de imágenes puede derivar en una indigestión icónica o una una iconoadicción, algo similar a lo que sucede con las drogas, explica Browne (2017), generando un efecto narcotizante y una especie de teleadicción o teledependencia. Incluso habla de "Iconorrea" para crear un símil entre la indigestión fisiológica y la saturación mental por las imágenes.

\subsection{Imágenes de Salud y Enfermedad.}

La construcción de la imagen de la enfermedad en el paciente puede explicarse también a través del modelo mental o contexto que propone Van Dijk (2001). Estas representaciones mentales controlan el evento comunicativo y regulan las relaciones entre el discurso y su ambiente social-cognitivo, asegurando los componentes apropiados de acuerdo a la situación. También existen conocimientos compartidos (Common Ground) que manejan la estructura compleja de lo implícito y lo explícito del discurso, así como las presuposiciones e implicaciones. En todo este proceso es también relevante el tratamiento que los medios informativos dan a los contenidos noticiosos, ya que estas constribuyen en la construcción de la imagen social de las enfermedades y de quienes están afectados por ellas (García, 2013).

Los modelos personales de la enfermedad incluyen entre sus elementos a las creencias que se han ido construyendo, lo que se traduce en que el afectado actúa a partir de la representación mental (cognitiva o emocional) que posee sobre la patología y no tanto a partir de los síntomas o la evidencia objetiva que posee, todo "con el objetivo de dotarla de sentido en una visión o interpretación personal de la condición y, a partir de esta interpretación, manejar lo más apropiadamente el problema"(Castillo, 2016, p.43).

Dentro de los aspectos más relevantes de las enfermedades crónicas no transmisibles está su extensión por largos periodos, ser asintomáticas en las primeras etapas, afectar la vida cotidiana y ser solo monitoreables, porque no tienen cura 
(Espinosa y Ordúñez, 2010). Quienes las padecen, tienen poca consciencia del autocuidado, lo que genera que entre el 30 al $80 \%$ de ellos deje de tomar sus fármacos a los seis meses de haber iniciado el tratamiento. Este abandono, que puede explicarse en la vivencia asintomática inicial y en las concepciones sobre la enfermedad, es también amplificado por la construcción a cargo de los medios de comunicación y de la educación recibida (Facchini, 2004). En consecuencia, la ausencia de síntomas molestos y una subestimación de la gravedad de la enfermedad explican la baja frecuencia de visitas al médico (Castillo-Morejón, Martín-Alonso y AlmenaresRodríguez, 2017).

Las imágenes mentales reflejan las creencias que las personas tienen sobre su enfermedad, explicando sus miedos, preocupaciones e incluso la esperanza de una recuperación. Sin embargo, no está claro si estas imágenes se originan en la influencia que ejercen los profesionales de la salud o en las creencias culturales sobre una u otra patología (Harrow, Wells, Humphris, Taylor y Williams, 2007).

Por ejemplo, resultados han sustentado que la representación de las personas con diabetes no es concordante con la visión biomédica que define la historia natural y el curso de la enfermedad. Lo anterior principalmente porque no se considera a los procesos emocionales, los cambios de vida, las creencias religiosas y la posibilidad de curación de los afectados (Torres-López, Sandoval-Díaz y Pando-Moreno,2005).

En la misma línea, reportes han dado cuenta de las percepciones sobre el sobrepeso y obesidad en mujeres, concluyendo que su imagen mental las hace pensar que su IMC (Indice de masa corporal) es normal y no son concientes de su problema nutricional (Rodríguez-Guzmán, Carballo-Gallegos, Coria, Arias-Flores y Puig-Nolasco, 2010).

\section{CONCLUSIONES}

La comunicación entre el médico y el enfermo crónico es una de las principales herramientas a utilizar para construir imágenes mentales de patologías como la diabetes, la dislipidemia o la hipertensión. Lo anterior, en un contexto de asintomatología, que requerirá de tratamientos prolongados, donde el establecimiento de un vínculo básico es fundamental para la acción terapéutica (Facchini, 2004).

Los profesionales de la salud deben doblar los esfuerzos para construir imágenes mentales junto a los enfermos de manera tal de promover la asertividad y adherencia en los subsecuentes tratamientos, orientándolos hacia la prevención de las complicaciones, el cumplimiento de las indicaciones y, de esta forma, ayudarlos a administrar su enfermedad.

Durante décadas, el modelo biomédico se ha caracterizado por presentar al paciente como un individuo separado del ambiente o del lugar de donde proviene, olvidando que las imágenes mentales constituyen representaciones internas del conocimiento y vinculan a las personas con su entorno. Eso nos lleva a concluir que cada individuo trae distintas representaciones internas, las que dependen de su contexto social, cultural y 
económico; y donde su percepción permite interpretar y entender la información recibida a través de los sentidos (Fuentemayor y Villasmil, 2008).

En el análisis de este problema no debe desconocerse la posibilidad de una errónea autopercepción de la salud, teniendo los medios de comunicación y las redes sociales un severo impacto en la población. Dichos medios y plataformas de información, en ocasiones pueden incluso distorsionar la percepción del sujeto, al grado de provocar una reacción patológica, una iconorrea (Browne, 2006) pero esta vez, en un contexto tan delicado como es la salud y el bienestar del individuo.

Todo lo expuesto anteriormente obliga a repensar y replantear la comunicación interpersonal en el ámbito de salud, donde se sumen más visiones a lo que conocemos como relación médico-paciente y dando paso a estrategias innovadoras en el ámbito de la psicología cognitiva, la educación sanitaria y los estudios culturales. Está claro que el actual acercamiento biomédico enmascarado en un modelo biopsicosocial no está dando respuestas en aspectos y desafíos puntuales de la medicina moderna.

Los nuevos especialistas de la salud primaria tendrán que generar junto a los pacientes, una co-construcción de las imágenes mentales de sus enfermedades. Esta nueva visión, implica que el profesional deberá insertarse en el contexto del paciente y desde ahí iniciar una exploración y explicación de cada realidad. Las creencias religiosas y étnicas, los factores socio-culturales asociados al territorio- como la extrema ruralidad o la marginalidad urbana- son algunos de los elementos a considerar con similar importancia a la dosis farmacológica, la evaluación nutricional o el ejercicios físico. Lo anterior recordando siempre que la falta de adherencia terapéutica es un problema multidimensional, donde las ideas o representaciones que tienen los pacientes sobre las enfermedades que sufren y sobre el tratamiento que les prescriben marcan su pronóstico (Ramos, 2015).

Este enfoque debe ser abordado en pregrado y en la formación clínica de los futuros médicos, enfermeras, psicólogos, nutricionistas, kinesiólogos y técnicos paramédicos. Los esfuerzos e innovaciones anteriormente mencionadas no tendrán sentido si el Estado a través de su enfoque y políticas públicas no es capaz de abordar el tratamiento de las enfermedades en una lógica holística abandonando el acercamiento meramente farmacológico y terapéutico. Así también es esencial que los sistemas educacionales sean innovadores e inclusivos y que los modelos de desarrollo permitan superar las brechas económicas asociadas.

\section{REFERENCIAS}

Baitello, N. (2004). Las cuatro devoraciones. Iconofagia y antropofagia en la comunicación y la cultura. Comunicación: Revista Internacional de Comunicación Audiovisual, Publicidad y Literatura, 1 (2), 159-168. Recuperado de http://hdl.handle.net/11441/57556

Baitello, N. (2005). A era da iconofagia: ensaios de comunicacao e cultura. São Paulo: Hacker. 
El desafío de construir imágenes mentales de las enfermedades crónicas no transmisibles en pacientes asintomáticos

Ballesteros, S. (1999). Memoria humana: investigación y teoría. Psicothema, 11 (4),705723. Recuperado de http://www.psicothema.com/psicothema.asp?id=323

Belting, H. (2007). Antropología de la imagen. Madrid: Katz editores.

Browne, R. (2006). Leyes (Neo) Totémicas y Sociedades de Discurso: Antecedentes para la Iconofagia. Revista Internacional de Comunicación Audiovisual, Publicidad y Literatura, 1 (1), 277-290. Recuperado de http://www.revistacomunicacion.org/pdf/n1/LEYES NEOTOTEMICAS Y SOCIEDADES DE DISCURSOS ANTECEDENTES PARA LA ICONOFAGIA.pdf

Browne, R. (2017). Comunicación indisciplinada: iconofagia e iconorrea en los medios de (in)comunicación. Revista Austral de Ciencias Sociales, 11, 101-114. Recuperado de https://dialnet.unirioja.es/servlet/articulo? codigo=2251335

Castillo, A. D. (2016). Representaciones cognitivas y emocionales del cáncer y la hipertensión: Aplicaciones del modelo de autorregulación en población sana (Tesis Doctoral Programa Oficial de Doctorado en Diseños y Aplicaciones en Psicología y Salud, Granada, España). Recuperado de https://digibug.ugr.es/handle/10481/43570

Castillo-Morejón, M., Martín-Alonso, L., y Almenares-Rodríguez, K. (2017). Adherencia terapéutica y factores influyentes en pacientes con diabetes mellitus tipo 2. Revista Cubana de Medicina General Integral, 33 (4), 1-10. Recuperado de https://www.medigraphic.com/cgi-bin/new/resumen.cgi?IDARTICULO=79094

Campos, A., y González, M. Á. (2017). Importancia de las imágenes mentales en el pensamiento. Revista Mexicana de Investigación en Psicología, 9 (2), 113-119. Recuperado de https://www.medigraphic.com/cgibin/new/resumen.cgi?IDARTICULO $=77018$

Espinosa, A., y Ordúñez, P. (2010). Necesidad de integración de salubristas, epidemiólogos y clínicos en la atención de pacientes con enfermedades crónicas. Revista Cubana de Salud Pública, $36 \quad$ (3), 262-266. Recuperado de http://scielo.sld.cu/scielo.php?script=sci arttext\&pid=S0864-34662010000300011

Facchini, M. (2004). Cambio de conductas en tratamientos de larga duración: relación médico-paciente. Medicina, $64 \quad$ (6), 550-554. Recuperado de https://www.medicinabuenosaires.com/demo/revistas/vol6404/6/CAMBIO\%20DE\%20CONDUCTAS\%20EN\%20TRATAMIENTOS\%20DE\%20LARG A\%20DURACION.PDF

Fernández, C. I. (2013). Influencia de la imagen mental en el aprendizaje. Revista Iberoamericana de Educación, 62 (1), 1-8. doi: https://doi.org/10.35362/rie621888

Fuenmayor, G. \& Villasmil, Y. (2008). La percepción, la atención y la memoria como procesos cognitivos utilizados para la comprensión textual. Revista de Artes y Humanidades UNICA, 9 (22),187-202. Recuperado de https://www.redalyc.org/articulo.oa?id=170118859011 
El desafío de construir imágenes mentales de las enfermedades crónicas no transmisibles en pacientes asintomáticos

García, I. M. (2013). Los medios de comunicación y la construcción de la imagen social de las enfermedades congénitas y crónicas: El caso de la esclerosis múltiple. Cuadernos de Gestión de Información, 2, 105-114. Recuperado de https://revistas.um.es/gesinfo/article/view/207671

Harrow, A., Wells, M., Humphris, G., Taylor, C. \& Williams, B. (2008). Seeing is believing, and believing is seeing: an exploration of the meaning and impact of women's mental images of their breast cancer and their potential origins. Patient Education and Counseling, 73 (2), 339-346. doi: https://doi.org/10.1016/i.pec.2008.07.014

Herrero, C. (2005). Mujer y medios de comunicación: Riesgos para la salud. Trastornos de la conducta alimentaria, 1 , 55-75. Recuperado de http://www.tcasevilla.com/archivos/mujer y medios de comunicacion riesgos para la salud.doc

Martínez, N. T. (2014). Imaginería mental: neurofisiología e implicaciones en psiquiatría. Revista Colombiana de Psiquiatría, 43 (1), 40-46. doi: https://doi.org/10.1016/S0034$\underline{7450(14) 70041-1}$

Moiso, A. (2007). Enfermedades crónicas no transmisibles: El desafío del siglo XXI. En A. Moiso, M. A. Mestorino, y O. A. Ojea (Eds.), Fundamentos de la salud pública (pp. 265280). La Plata: EDULP Ediciones.

Otero, M. R. (2016). Psicología cognitiva, representaciones mentales e investigación en enseñanza de las ciencias. Investigações em Ensino de Ciências, 4 (2), 93-119. Recuperado de https://www.if.ufrgs.br/cref/ojs/index.php/ienci/article/view/651

Pardos, A. (2017). Las imágenes en el pensamiento. Revista Mexicana de Investigación en $\begin{array}{llll}\text { Psicología, } & 9 & \text { (2), }\end{array}$ http://www.revistamexicanadeinvestigacionenpsicologia.com/index.php/RMIP/article/view $\underline{1263}$

Pech, S. W., Baeza, J. E. y Ravell, M. J. (2010). Factores que inciden en el fracaso del tratamiento del paciente diabético en Tekax, Yucatán, México. Revista de Especialidades Médico-Quirúrgicas, 15 (4), 211-215. Recuperado de https://www.medigraphic.com/caibin/new/resumen.cgi?IDARTICULO=30087

Peralta, M. L. y Carbajal, P. (2008). Adherencia a tratamiento. Revista del Centro Dermatológico Pascua, 17(3), 84-88. Recuperado de https://www.medigraphic.com/cgibin/new/resumen.cgi?IDARTICULO=19137

Ramos, M. L. (2015). La adherencia al tratamiento en las enfermedades crónicas. Revista Cubana de Angiología y Cirugía Vascular, 16 (2), 175-189. Recuperado de https://www.medigraphic.com/cgi-bin/new/resumen.cgi?IDARTICULO=60591

Rodríguez-Guzmán, L. M., Carballo-Gallegos, L. F., Coria, F., Arias-Flores, R. y PuigNolasco, Á. (2010). Autopercepción de la imagen corporal en mujeres y su correlación con el índice de masa corporal. Medicina Universitaria,12 (46), 29-32. Recuperado de http://eprints.uanl.mx/id/eprint/8288 
Soto, A. (2015). Las imágenes en el pensamiento de Vilém Flusser. Paradigma: Revista Universitaria de Cultura, 18, 38-47. Recuperado de http://hdl.handle.net/10630/8829

Torres, T. (2002). Una aproximación cualitativa al estudio de las enfermedades crónicas: las representaciones sociales. Revista Universidad de Guadalajara [Dossier de Ciencias Sociales y Ciencias de la Salud].

Torres-López, T. M., Sandoval-Díaz, M., y Pando-Moreno, M. (2005). Sangre y azúcar: representaciones sobre la diabetes de los enfermos crónicos en un barrio de Guadalajara, México. Cadernos de Saúde Pública, 21 (1), 101-110. doi: https://doi.org/10.1590/S0102-311X2005000100012

Van Dijk, T. (2001). Algunos principios de una teoría del contexto. Revista Latinoamericana de Estudios del Discurso, 1 (1), 69-81. Recuperado de http://discursos.org/oldarticles/Algunos\%20principios\%20de\%20una\%20teor\%EDa\%20d el\%20contexto.pdf

Villafañe, J. (1992). Introducción a la teoría de la imagen. Madrid: Pirámide.

\section{AUTORES}

\section{Miguel Ángel Carrasco Garcia.}

Universidad Austral de Chile- Universidad de la Frontera. Periodista y Médico Cirujano de la Universidad Austral de Chile (UACH). Diplomado en medicina Familiar, Universidad de la Frontera (UFRO). MBA en Salud, Universidad Andrés Bello. Estudiante Magister en Gerontología Clínica de la Universidad Mayor. Estudiante Doctorado en Comunicación UACH-UFRO miguel.carrasco@alumnos.uach.cl

ORCID ID: https://orcid.org/0000-0003-4657-6390

\section{Ricardo Andres Neira Mellado.}

Universidad Austral de Chile. Chile. Cirujano Dentista egresado de la universidad de Concepción (2005). Especialista en Rehabilitación Oral de la Universidad del Desarrollo, Chile (2010). Magíster en Pedagogía Universitaria y Educación Superior, Universidad Mayor. Chile (2012). Docente Adjunto del Instituto de OdontoEstomatología, Facultad de Medicina, Universidad Austral de Chile.

ricardo.neira@uach.cl

ORCID ID: https://orcid.org/0000-0002-3693-226X

\section{Paulina Lisbett Fierro Pinot.}

Profesora de educación general básica, licenciada en educación de la Pontificia Universidad Católica de Chile. Psicóloga de la Universidad del Aconcagua. Diplomada en Aplicación de Terapia Sistémica Breve del Centro de Estudios Sistémicos de Concepción.

paulylis@hotmail.com 